\title{
$X$-ray Photoelectron Spectroscopic Study on the Anodic Passivity of Sputter-deposited W-Nb Alloys in 12 M HCl Solution
}

\author{
J. Bhattarai* \\ Central Department of Chemistry, Tribhuvan University, Kirtipur, Kathmandu, Nepal
}

Received4 March 2011, accepted in final revised form 10 June 2011

\begin{abstract}
The effect of a simultaneous additions of tungsten and niobium on the anodic passivity of the surface films of the sputter-deposited amorphous/nanocrystalline $\mathrm{W}$-xNb alloys was studied using corrosion tests, electrochemical measurements and X-ray photoelectron spectroscopic (XPS) analyses. The formation of spontaneous passive film on the alloys, which is composed of double oxyhydroxides of $\mathrm{W}^{\mathrm{ox}}$ and $\mathrm{Nb}^{5+}$ ions, is responsible for their higher corrosion resistance than those of the alloy-constituting elements in $12 \mathrm{M} \mathrm{HCl}$ solution open to air at $30^{\circ} \mathrm{C}$. The quantitative surface analysis by XPS clarifies that the improved anodic passivity of the alloys than those of alloy-constituting elements is based on the formation of new double oxyhydroxide anodic films composed of $\mathrm{W}^{6+}$ and $\mathrm{Nb}^{5+}$ ions. These anodic passive films have higher protectiveness and stability than those of the anodic passive oxyhydroxide films of alloy-constituting elements, that is, oxyhydroxides of hexavalent tungsten and pentavalent niobium after potentiostatic polarization for $1 \mathrm{~h}$ in 12 $\mathrm{M} \mathrm{HCl}$ at $30^{\circ} \mathrm{C}$.

Keywords: W-Nb alloys; Sputter deposition; Polarization curve; Passivity; Surface analysis.

(c) 2011 JSR Publications. ISSN: 2070-0237 (Print); 2070-0245 (Online). All rights reserved.

doi:10.3329/jsr.v3i3.7207 J. Sci. Res. 3 (3), 457-470 (2011)
\end{abstract}

\section{Introduction}

The passivity of metals or alloys is a subject of significant research in the fields of corrosion science and engineering. The mechanisms of passive film formation and the nature of the passive films can be understood by modern electrochemical theories with the aid of potentiostatic or/and galvanostatic polarization measurements. The change in the current density as a function of polarization potential (that is, deviation of potentials away from equilibrium) represented in the polarization diagrams, and several processes related to corrosion and passivation can be easily understood with the help of the polarization diagrams of the alloys or metals. It must be remembered that experiments have to be performed by controlling the potential and measuring the current (that is, either by

\footnotetext{
*Corresponding author: bhattarai_05@yahoo.com
} 
potentiostatically or potentiodynamically) in order to understand the anodic passivity of the alloys or metals [1]. The measurement of the anodic potentiodynamic or/and potentiostatic polarization curves gives us a clear understanding as to what conditions are necessary to achieve the stable anodic passivity and the high corrosion resistance of the metals or alloys in the given aggressive environments. However, the polarization curves only do not provide any reply to the question as to why the metals or alloys show a low corrosion rate in the passive state and resists in a wide variety of corrosive environments. The only answer to above question is that there exists a superior protective passive films formed on the surfaces of the alloys or metals by knowing the compositions of the surface films formed on the materials in the given corrosive environments.

The formation of anodic passive films formed on the metals or alloys has gained great scientific interest for a long period. It is important from a practical point of view that the anodic film causes the passivity. The passivity of metals or alloys mostly concerns the corrosion resistance and hence the interest is focused on the chemical as well as electrochemical stability of the anodic passive films [2]. On the other hand, the breakdown of the anodic passive films has been the subject of many investigations on the anodic passivity of metals or alloys. The pitting corrosion is one of the most common and dangerous types of localized corrosion of the anodic films formed on the metals or alloys. Therefore, the immunity to pitting corrosion is one of the most interesting characteristics of the passivity of the metals or alloys.

The passivating elements such as tungsten and niobium can generally improve corrosion resistance of alloys. The properties of the anodic passive films formed on tungsten metal have previously been reported, where the anodic film of tungsten showed a duplex structure consisting of an inner amorphous barrier-type anodic $\mathrm{WO}_{3}$ film and outer porous crystalline layer [3]. An insulating layer of $\mathrm{WO}_{3}$ was formed by anodic polarization of tungsten in acidic environments [4]. Several surface studies have been carried out for an understanding of the role of the tungsten in the passivation mechanisms of stainless steels in aggressive chloride media [5-9]. On the other hand, niobium is widely known for its superior corrosion resistance behavior in aggressive acidic media. In particular, niobium is corrosion resistance in oxidizing environments. Anderson et al. studied the corrosion behavior of the sputter-deposited amorphous $\mathrm{Ni}-\mathrm{Nb}$ coatings on commercial 316L stainless steel in different aggressive media and they found that the amorphous Ni-Nb coatings have good corrosion resistance [10]. It has been reported that the alloying of niobium with copper [11], aluminum [12], chromium [13], molybdenum [14] and magnesium [15] enhances the protective quality of the passive films in aggressive media. The sputter-deposited Cu-Nb [11], Al-Nb [12] and Mg-Nb [15] alloys were spontaneously passivated and showed high corrosion resistance in aggressive media even though these alloys did not show higher corrosion resistance than those of alloy-constituting elements. However, the most interesting fact has been reported, during last two decades, that the corrosion rates of the sputter-deposited $\mathrm{Cr}-\mathrm{Nb}[13,16,17]$ and Mo-Nb [14,17] alloys were lower than those of alloy constituting elements due to the 
spontaneous passivation in aggressive $\mathrm{HCl}$ solutions. Such interesting findings of the lower corrosion rates of $\mathrm{Cr}-\mathrm{Nb}$ and $\mathrm{Mo}-\mathrm{Nb}$ alloys than those of alloy constituting elements encouraged the present author to tailor high corrosion resistance $\mathrm{W}-\mathrm{Nb}$ alloys by sputtering [18-21].

It has been reported that the high corrosion resistance of the sputter-deposited tungsten-based binary [18-20, 22-25] and ternary [26,27] alloys in $12 \mathrm{M} \mathrm{HCl}$ was based on the formation of new passive double oxyhydroxide films of tetravalent tungsten and alloy-constituting cations. The tetravalent tungsten is the main oxidation state of tungsten for these tungsten-based binary alloys at $+0.2 \mathrm{~V}$ (SCE) or lower potentials, while the hexavalent tungsten is the main oxidation state of tungsten at $+0.4 \mathrm{~V}$ (SCE) or higher potentials in hydrochloric acid solutions. According to Habazaki et al. [28], the passive film on tungsten was tetravalent tungsten oxyhydroxide and hexavalent tungsten oxyhydroxide was not the true passive film. However, the transpassivation of tungsten is clearly different from those of chromium and molybdenum. Transpassivation of chromium and molybdenum was resulted in sharp increases in the anodic current density in $12 \mathrm{M} \mathrm{HCl}$ solution $[13,14,29]$. By contrast, the present author has been reported in polarization curves of tungsten and tungsten-based binary alloys that the oxidation from the tetravalent state to the hexavalent state of tungsten did not lead to the transpassivation, although the anodic current density was significantly high. In this context, it is necessary and interesting to study the potential dependence of the surface composition of the anodic passive films of the sputter-deposited $\mathrm{W}$-xNb alloys to clarify the mechanisms of the anodic passivity of the binary alloys in hydrochloric acid solutions.

Varieties of techniques are used by corrosion scientists to study the chemical nature and stability of the passive films formed on the alloys. X-ray photoelectron spectroscopic (XPS) technique has been widely used in this field and has proved to be one of the promising methods in investigating the chemical composition and the oxidation states of the alloy-constituting elements in the passive films as well as the compositions of the alloy surfaces. Therefore, the combination of electrochemical measurements with XPS seems to be more effective in studying the passivation behavior of the corrosion-resistant alloys.

The present research work is aimed to characterize the surface composition as well as the structure of the anodic passive films formed on the sputter-deposited binary $\mathrm{W}$-xNb ( $\mathrm{x}$ = 26, 62 and 78 atomic percentage, at\%) alloys after potentiostatic polarization for $1 \mathrm{~h}$ in $12 \mathrm{M} \mathrm{HCl}$ solution open to air at $30^{\circ} \mathrm{C}$ using immersion tests, electrochemical measurements and X-ray photoelectron spectroscopic (XPS) analyses.

\section{Experimental Methods}

The sputter-deposited nanocrystalline $\mathrm{W}-26 \mathrm{Nb}$, and amorphous $\mathrm{W}-62 \mathrm{Nb}$ and $\mathrm{W}-78 \mathrm{Nb}$ alloys having the apparent grain size of about 24 and $1.6 \mathrm{~nm}$, respectively, were used to 
conduct the present research work. The details about the preparation and characterization of these three alloys have been reported elsewhere [18,19,30].

Prior to immersion tests, electrochemical measurements and XPS analyses, the surfaces of the alloy specimens were mechanically polished with a silicon carbide paper up to grit number 1500 in cyclohexane, rinsed by acetone and dried in air. The average corrosion rate of the alloys was estimated from the weight loss after immersion for $168 \mathrm{~h}$ in $12 \mathrm{M} \mathrm{HCl}$ solution open to air at $30^{\circ} \mathrm{C}$. Open circuit immersion and potentiostatic polarization at several potentials for $1 \mathrm{~h}$ in $12 \mathrm{M} \mathrm{HCl}$ solution were carried out. A platinum mesh and a saturated calomel electrode (SCE) were used as counter and reference electrodes, respectively. All the potentials given in this paper are relative to SCE.

Before and after open circuit immersion or potentiostatic polarization, composition of the surface films of the alloy specimens was analyzed using XPS (Shimadzu ESCA-850 photoelectron spectrometer). The XPS spectra over a wide binding energy region (0-1000 $\mathrm{eV}$ ) were exhibited peaks of chlorine, carbon, oxygen, tungsten and niobium. The integrated intensities of the $\mathrm{C} 1 \mathrm{~s}, \mathrm{O} 1 \mathrm{~s}, \mathrm{~W} 4 \mathrm{f}$ and $\mathrm{Nb} 3 \mathrm{~d}$ spectra were separately obtained for the quantitative surface analysis as described elsewhere [18-20]. For the specimen polarized or immersed in $12 \mathrm{M} \mathrm{HCl}$ solution, the $\mathrm{Cl} 2 \mathrm{p}$ spectrum was detected at about $199 \mathrm{eV}$, which comes from chloride ions. However, the intensity of the $\mathrm{Cl} 2 \mathrm{p}$ peak was very low and hence the concentration of chloride ions was not considered in the calculation. The binding energies of the electrons were calibrated using the method described elsewhere [31,32]. The peak binding energies of each peak were further corrected using the energy value of $285 \mathrm{eV}$ for $\mathrm{C} 1$ s electron state. The composition and thickness of anodic passive films and the composition of the underlying alloy surface were quantitatively determined by a previously proposed method [31] using integrated intensities of photoelectrons under the assumption of a three layer model of the outermost contaminant hydrocarbon layer of uniform thickness, the surface film of uniform thickness and the underlying alloy surface of X-ray photoelectron spectroscopically infinite thickness. The photoionization cross-section of the $\mathrm{W}$ 4f and $\mathrm{Nb} 3 \mathrm{~d}$ electrons relative to the $\mathrm{O}$ 1s electrons used were 2.97 [33] and 2.981 [34], respectively.

\section{Results and Discussion}

\subsection{Corrosion behavior and passivity of $W-x N b$ alloys}

The corrosion rates of the sputter-deposited amorphous or nanocrystalline $\mathrm{W}$-xNb alloys and alloy-constituting elements were estimated from weight losses after immersion for about one week in $12 \mathrm{M} \mathrm{HCl}$ solution open to air at $30^{\circ} \mathrm{C}$. The weight loss for each specimen was estimated two times or more and the average corrosion rate was calculated. Fig. 1 shows the average corrosion rates of the $\mathrm{W}-26 \mathrm{Nb}, \mathrm{W}-62 \mathrm{Nb}$ and $\mathrm{W}-78 \mathrm{Nb}$ alloys after immersion for $168 \mathrm{~h}$ in $12 \mathrm{M} \mathrm{HCl}$. The corrosion rates of the sputter-deposited 
tungsten and niobium are also shown for comparison. All the examined binary $\mathrm{W}-\mathrm{xNb}$ alloys in the present study show higher corrosion resistance than those of alloy-constituting elements in $12 \mathrm{M} \mathrm{HCl}$ solution. The $\mathrm{W}-26 \mathrm{Nb}$ and $\mathrm{W}-62 \mathrm{Nb}$ alloys show about one order of magnitude lower corrosion rates (that is, $4-5 \times 10^{-3} \mathrm{~mm} / \mathrm{y}$ ) than those of alloy-constituting elements (that is, sputter-deposited tungsten and niobium). However, the corrosion rate of the $\mathrm{W}-78 \mathrm{Nb}$ alloy shows slightly lower corrosion resistance than those of $\mathrm{W}-26 \mathrm{Nb}$ and $\mathrm{W}-62 \mathrm{Nb}$ alloys. These results clearly reveal that the corrosion resistance of the $\mathrm{W}-\mathrm{xNb}$ alloys is surprisingly improved in $12 \mathrm{M} \mathrm{HCl}$ solution open to air at $30^{\circ} \mathrm{C}$. Consequently, it can be said that both tungsten and niobium improve the corrosion resistance of the $\mathrm{W}$-xNb alloys synergistically.

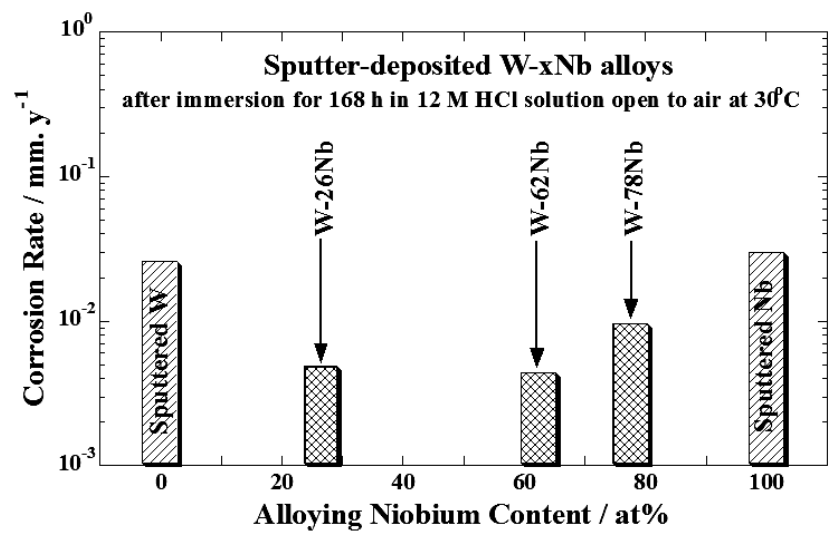

Fig. 1. Corrosion rates of the sputter-deposited $\mathrm{W}$-xNb alloys including tungsten and niobium after immersion for $168 \mathrm{~h}$ in $12 \mathrm{M} \mathrm{HCl}$ solution open to air at $30^{\circ} \mathrm{C}$.

Potentiostatic polarization measurement was carried out for the $\mathrm{W}$-xNb alloys to gain a better understanding of the anodic passivity of the alloys. Figs. 2 (a) and 2 (b) show the changes in anodic current densities of the $\mathrm{W}-26 \mathrm{Nb}$ and $\mathrm{W}-62 \mathrm{Nb}$ alloys, respectively, after potentiostatic polarization at different potentials for $1 \mathrm{~h}$ in $12 \mathrm{M} \mathrm{HCl}$ solution open to air at $30^{\circ} \mathrm{C}$, as a function of polarization time. The anodic current densities of the $\mathrm{W}-26 \mathrm{Nb}$ alloy at each potential except at $0.2 \mathrm{~V}$ (SCE) are very slightly decreased with polarization up to about 5 minutes and then the current density becomes almost steady state with polarization time as shown in Fig. 2 (b). This result indicates that initially the dissolution of the tungsten-rich $\mathrm{W}-26 \mathrm{Nb}$ alloy occurs and then the protective anodic passive film is formed. However, the trend of the change of anodic current density on the niobium-rich $\mathrm{W}-62 \mathrm{Nb}$ alloy is different with polarization time as shown in Fig. 2 (b). The anodic current densities of the $\mathrm{W}-62 \mathrm{Nb}$ alloy at all polarization potentials tend to decrease with polarization time till about 1-2 minutes and become almost steady. According, the 
protective quality of the anodic passive films formed on the sputter-deposited niobiumrich $\mathrm{W}-62 \mathrm{Nb}$ increased with polarization time in $12 \mathrm{M} \mathrm{HCl}$ solution open to air at $30^{\circ} \mathrm{C}$.

Fig. 3 shows the potentiostatic anodic and cathodic polarization curves for the sputterdeposited $\mathrm{W}-26 \mathrm{Nb}, \mathrm{W}-62 \mathrm{Nb}$ and $\mathrm{W}-78 \mathrm{Nb}$ alloys including the sputter-deposited niobium metal after potentiostatic polarization at different potentials for $1 \mathrm{~h}$ in $12 \mathrm{M} \mathrm{HCl}$ solution open to air at $30^{\circ} \mathrm{C}$. Spontaneous passivation occurs for all three $\mathrm{W}$-xNb alloys including niobium metal. The open circuit potentials of the alloys locate between the open circuit potentials of the $\mathrm{W}-26 \mathrm{Nb}$ alloy and the niobium metal. The anodic current density of the alloys decreases with increasing the niobium content in the $\mathrm{W}$-xNb alloys in $12 \mathrm{M} \mathrm{HCl}$, indicating that the protectiveness of the anodic passive films of the $\mathrm{W}$-xNb alloys is better than that of tungsten metal. These facts are in agreement with higher corrosion resistance than those of alloy-constituting elements as shown in Fig. 1.

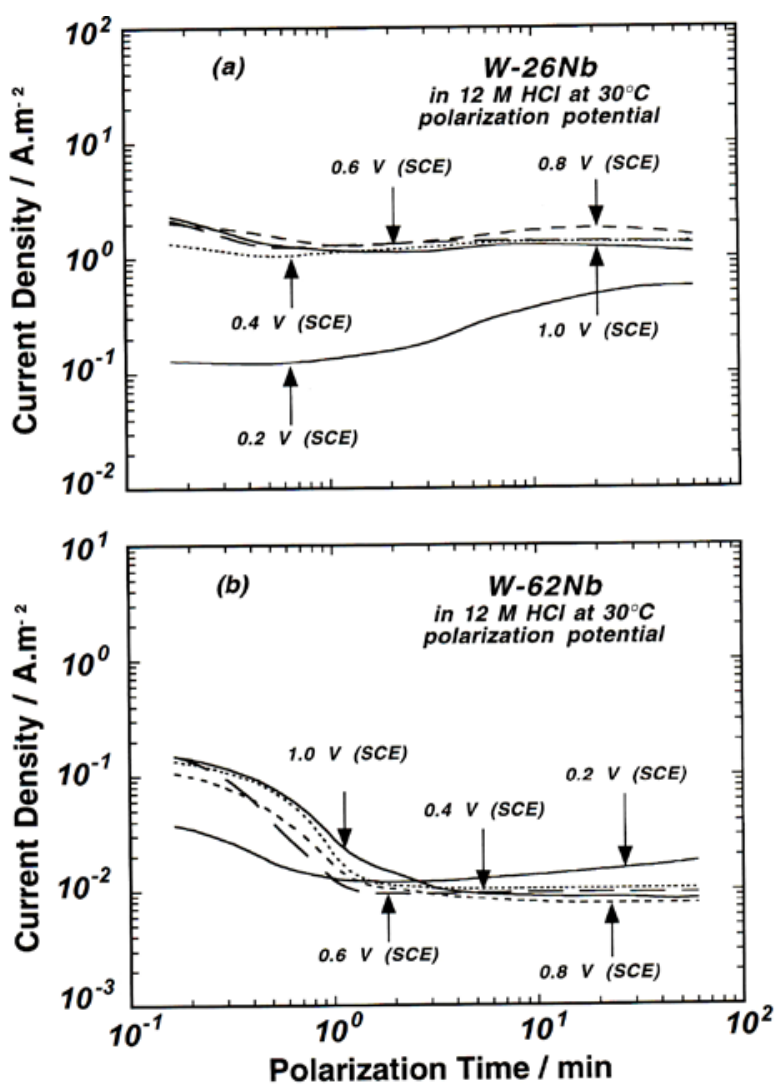

Fig. 2. The change in the anodic current density with polarization time for the sputter-deposited (a) $\mathrm{W}-26 \mathrm{Nb}$ and (b) $\mathrm{W}-62 \mathrm{Nb}$ alloys after potentiostatic polarization for $1 \mathrm{~h}$ in $12 \mathrm{M} \mathrm{HCl}$ solution open to air at $30^{\circ} \mathrm{C}$. 


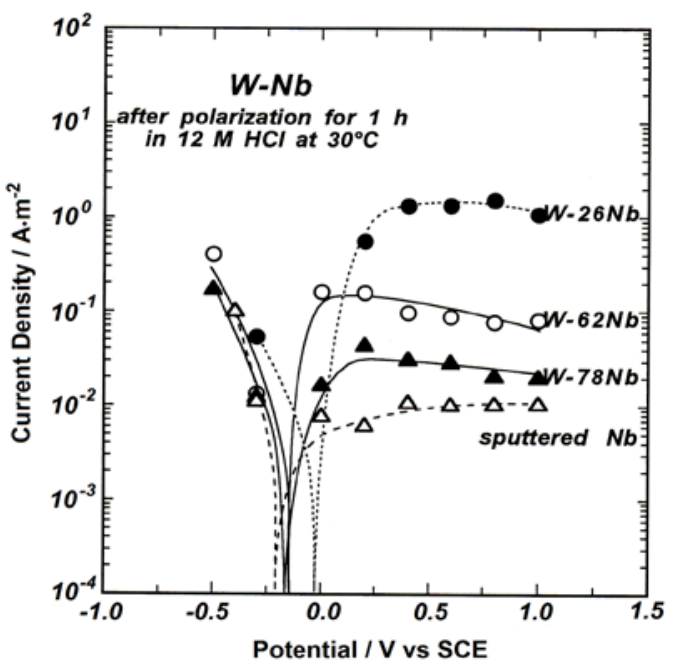

Fig. 3. Potentiostatic cathodic and anodic polarization curves for the sputter-deposited W-26Nb, W$62 \mathrm{Nb}, \mathrm{W}-78 \mathrm{Nb}$ alloys including niobium metal after potentiostatic polarization for $1 \mathrm{~h}$ in $12 \mathrm{M} \mathrm{HCl}$ at $30^{\circ} \mathrm{C}$.

\subsection{Surface composition and passivity of $W$-xNb alloys}

The surface analyses of the anodic passive films of the alloys give important information for a better understanding of the synergistic effect of tungsten and niobium in the anodic passivity of the sputter-deposited $\mathrm{W}$-xNb alloys. For this purpose, the surface of the $\mathrm{W}$-xNb alloys before and after immersion or potentiostatic polarization for $1 \mathrm{~h}$ in 12 $\mathrm{M} \mathrm{HCl}$ was analyzed using XPS. XPS spectra for $\mathrm{W}-\mathrm{xNb}$ alloys over a wide binding energy region, that is, $0-1000 \mathrm{eV}$, were exhibited peaks of tungsten, niobium, oxygen, carbon and chlorine. The $\mathrm{C} 1 \mathrm{~s}$ spectrum arises from a contaminant hydrocarbon layer covering the specimen surface was detected at about $285 \mathrm{eV}$. For the specimen polarized or immersed in $12 \mathrm{M} \mathrm{HCl}$ solution, the $\mathrm{Cl} 2 \mathrm{p}$ spectrum was detected at about $199 \mathrm{eV}$, which comes from chloride ions. However, the intensity of the $\mathrm{Cl} 2 \mathrm{p}$ peak was very low and hence the concentration of the chloride ion was not considered in the calculation for the surface analyses in the present study. The $\mathrm{O} 1 \mathrm{~s}$ spectrum is generally composed of two peaks; the lower binding energy peak at 530.2 - $5331.1 \mathrm{eV}$ is assigned to OM oxygen and the higher binding energy peak at 532.1 - $533.1 \mathrm{eV}$ arises from $\mathrm{OH}$ oxygen [31,32]. The $\mathrm{OM}$ oxygen corresponds to $\mathrm{O}^{2-}$ ions in oxyhydroxides or/and oxides. The $\mathrm{OH}$ oxygen is linked to hydrogen and is composed of $\mathrm{OH}$ ions and bound water in the surface film. An example of the deconvolution of the $\mathrm{O} 1 \mathrm{~s}$ spectrum measured for $\mathrm{W}-62 \mathrm{Nb}$ alloy is shown in Fig. 4. The $\mathrm{O}^{2-}$ peak is substantially more intense than the $\mathrm{OH}$ peak in the $\mathrm{O} 1 \mathrm{~s}$ spectrum for the alloys after immersion or potentiostatic polarization for $1 \mathrm{~h}$ in $12 \mathrm{M} \mathrm{HCl}$ solution open to air at $30^{\circ} \mathrm{C}$. Furthermore, the ratio of $\left[\mathrm{O}^{2-}\right] /[$ cations] increases with increasing anodic polarization potentials, while the ratio of $\left[\mathrm{OH}^{-}\right] /[$cations] decreases 
slightly with the anodic polarization potential for all the examined $\mathrm{W}$-xNb alloys. Accordingly, the anodic passive films on the $\mathrm{W}$-xNb alloys consisted of oxyhydroxides of both cations in which $\mathrm{O}^{2-}$ ion is the major oxygen species. The spectra from the alloy constituents indicated the presence of the oxidized and metallic species; the former comes from the surface film and the latter from the underlying alloy surface. The measured spectra of $\mathrm{W} 4 \mathrm{f}$ electrons and $\mathrm{Nb} 3 \mathrm{~d}$ electron states were separated into $\mathrm{W}^{6+}, \mathrm{W}^{5+}, \mathrm{W}^{4+}$ and $\mathrm{W}^{\mathrm{m}}$, and $\mathrm{Nb}^{5+}$ and $\mathrm{Nb}^{\mathrm{m}}$ state spectra, respectively, as discussed elsewhere in detail [19]. The integrated intensities of these $\mathrm{W} 4 \mathrm{f}$ and $\mathrm{Nb} 3 \mathrm{~d}$ spectra were separately obtained by the same method as that described elsewhere [18,31,32].

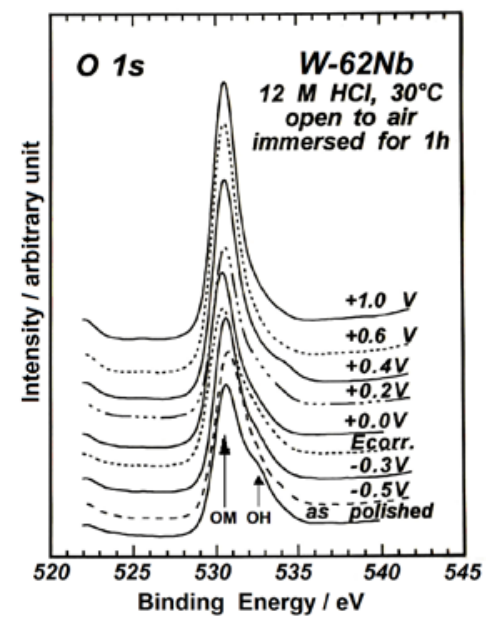

Fig. 4. An example of the deconvolution of $\mathrm{O}$ 1s spectra measured for the sputter-deposited W$62 \mathrm{Nb}$ alloy after immersion or potentiostatic polarization at different potentials for $1 \mathrm{~h}$ in $12 \mathrm{M} \mathrm{HCl}$ solution open to air at $30^{\circ} \mathrm{C}$.

The changes in the surface compositions of the anodic films of the $\mathrm{W}$-xNb alloys in 12 $\mathrm{M} \mathrm{HCl}$ solution were analyzed by XPS. Fig. 5 shows the changes in the cationic fractions in the surface films as a function of the polarization potential. The cationic fraction in the air-formed films on as-polished alloy specimens after mechanical polishing is also shown for comparison. XPS analysis for $\mathrm{W}$-xNb alloys after mechanical polishing shows that the air-formed films are enriched in niobium and deficient in tungsten with respect to the alloy composition, while the reverse was the results (not shown here) for the underlying alloy surface. This indicates that air exposure of the $\mathrm{W}$-xNb alloys results in preferential oxidation of niobium. Immersion for $1 \mathrm{~h}$ in $12 \mathrm{M} \mathrm{HCl}$ solution at $30^{\circ} \mathrm{C}$ results in the change in the composition of the surface films. Tungsten is significantly concentrated in the spontaneously passivated films on the $\mathrm{W}-26 \mathrm{Nb}$ and $\mathrm{W}-62 \mathrm{Nb}$ alloys after open circuit immersion for $1 \mathrm{~h}$ in $12 \mathrm{M} \mathrm{HCl}$, whereas the $\mathrm{W}-78 \mathrm{Nb}$ alloy shows almost the same cationic fraction as the alloy composition. However, it is meaningful for mentioning here that five hours immersion or more periods was resulted in preferential dissolution of 
niobium from the spontaneously surface films on all these three $\mathrm{W}$-xNb alloys and hence tungsten-enriched passive film was formed $[18,19]$.

There is no any change in the cationic fractions of tungsten and niobium in the anodic passive films with anodic polarization potential for the W-62Nb alloy. On the other hand, although a significant enrichment of tungsten ion is observed in the spontaneously passivated films at the open-circuit potential for $\mathrm{W}-26 \mathrm{Nb}$ and $\mathrm{W}-62 \mathrm{Nb}$ alloys, anodic polarization leads to an increase in the niobium content towards bulk compositions as shown in Fig. 5. The cationic composition of niobium increases with anodic polarization potential particularly for the $\mathrm{W}-26 \mathrm{Nb}$ and $\mathrm{W}-62 \mathrm{Nb}$ alloys when these alloys are polarized in the transpassive potential region of tungsten. As mentioned above in Fig. 4, the anodic passive films on the $\mathrm{W}$-xNb alloys after potentiostatic polarization at different polarization potentials consisted of oxyhydroxides of both cations in which $\mathrm{O}^{2-}$ ion is a major oxygen species. These results revealed that the anodic passive films on the $\mathrm{W}-\mathrm{xNb}$ alloys compose of oxyhydroxides of both $\mathrm{W}^{6+}$ and $\mathrm{Nb}^{5+}$ cations in which $\mathrm{O}^{2-}$ ion is remarkably higher than $\mathrm{OH}^{-}$ion.

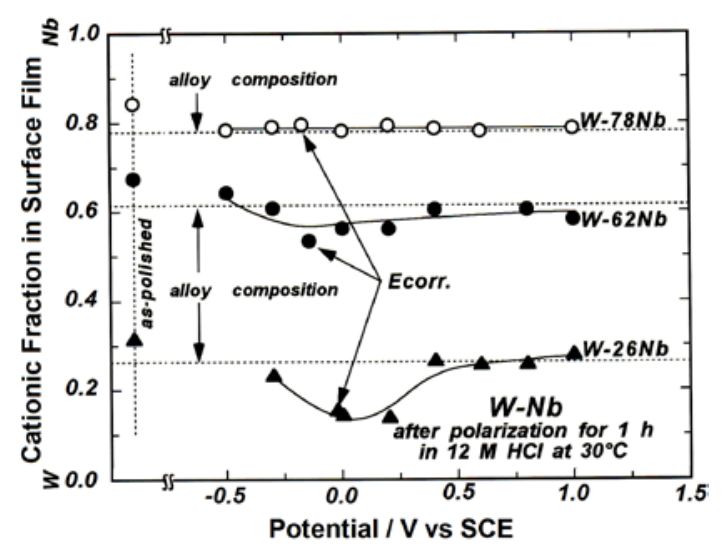

Fig. 5. Changes in cationic fractions in the surface films on the sputter-deposited $\mathrm{W}-26 \mathrm{Nb}$, $\mathrm{W}-62 \mathrm{Nb}$ and $\mathrm{W}-78 \mathrm{Nb}$ alloys after potentiostatic polarization for $1 \mathrm{~h}$ in $12 \mathrm{M} \mathrm{HCl}$ solution open to air at $30^{\circ} \mathrm{C}$, as a function of polarization potential.

\subsection{Anodic film thickening and distribution of tungsten ions on $W-x N b$ alloys}

It has been reported that the anodic polarization leads to thickening of the anodic passive films for the sputter-deposited binary tungsten-based alloys in hydrochloric acid solutions $[18,22]$. Remarkable anodic film thickening of the sputter-deposited tungsten-valve metal alloys was observed at $+0.2 \mathrm{~V}$ (SCE) or higher potentials. The distribution of both cations of the binary tungsten-valve metal alloys in the anodic passive films plays important roles in the film thickening of the alloys. Similarly, the change in different oxidation states of tungsten ions in the anodic film greatly affects the film thickening. Therefore, effects of 
cations of alloy-constituting elements, that is, tungsten ions and $\mathrm{Nb}^{5+}$ ions, in the anodic film thickening of the binary $\mathrm{W}$-xNb alloys are discussed here in detail. Fig. 6 shows the changes in the anodic film thickening of the $\mathrm{W}$-xNb alloys after potentiostatic polarization for $1 \mathrm{~h}$ in $12 \mathrm{M} \mathrm{HCl}$ solution open to air at $30^{\circ} \mathrm{C}$, as a function of potential. The anodic polarization on the $\mathrm{W}$-xNb alloys including sputter-deposited niobium leads to thickening of the anodic passive films. In particular, the anodic film thickening is clearly observed in the anodic potential range between 0.2 to $1.0 \mathrm{~V}$ (SCE).

The distribution of both cations of the binary $\mathrm{W}-\mathrm{xNb}$ alloys, that is, $\mathrm{W}^{\mathrm{ox}}$ and $\mathrm{Nb}^{5+}$ ions, in the anodic passivity of the alloys plays important roles in the film thickening of the alloys. Figs. 7(a) and 7(b) show quantitative results of the change in relative ratios of $\mathrm{W}^{4+}, \mathrm{W}^{5+}$ and $\mathrm{W}^{6+}$ ions in the passive films on the $\mathrm{W}-26 \mathrm{Nb}$ and $\mathrm{W}-62 \mathrm{Nb}$ alloys, respectively, as a function of polarization potential in $12 \mathrm{M} \mathrm{HCl}$ solution open to air at $30^{\circ} \mathrm{C}$ for $1 \mathrm{~h}$. For comparison, the ratios of tungsten ions on the as-polished specimens are also plotted. The major tungsten species is $\mathrm{W}^{4+}$ ion in the passive films at lower potentials but $\mathrm{W}^{6+}$ ion is in the air-formed film. On the other hand, an increase in the polarization potential results in an increase in the ratio of $\mathrm{W}^{6+}$ ion to the total tungsten ions because the $\mathrm{W}^{6+}$ ion is stable at high anodic potentials. The cationic composition in the anodic film is not largely different from the alloy composition as shown in Fig. 5, film thickening at anodic potentials is based on the formation of the oxyhydroxides of $\mathrm{W}^{6+}$ and $\mathrm{Nb}^{5+}$. Consequently, an anodic polarization result in the anodic film thickening is mostly due to increase in $\mathrm{W}^{6+}$ and $\mathrm{Nb}^{5+}$ ions.

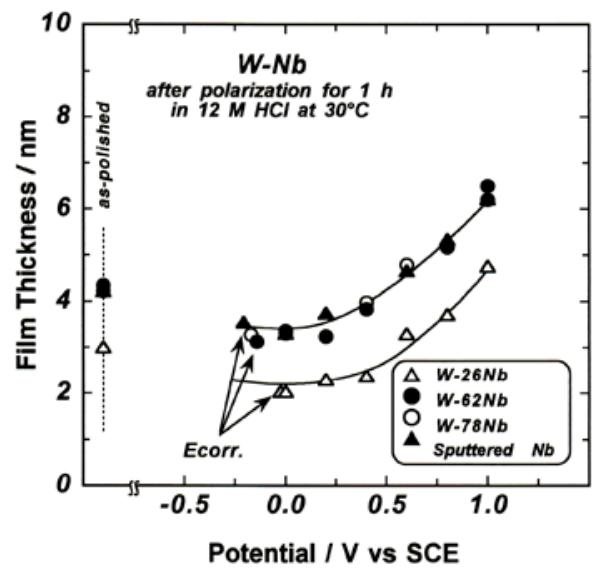

Fig. 6. Changes in thicknesses of the anodic films on the sputter-deposited W-26Nb, W-62Nb and $\mathrm{W}-78 \mathrm{Nb}$ alloys including niobium metal after potentiostatic polarization for $1 \mathrm{~h}$ in $12 \mathrm{M} \mathrm{HCl}$ solution open to air at $30^{\circ} \mathrm{C}$, as a function of polarization potential. 


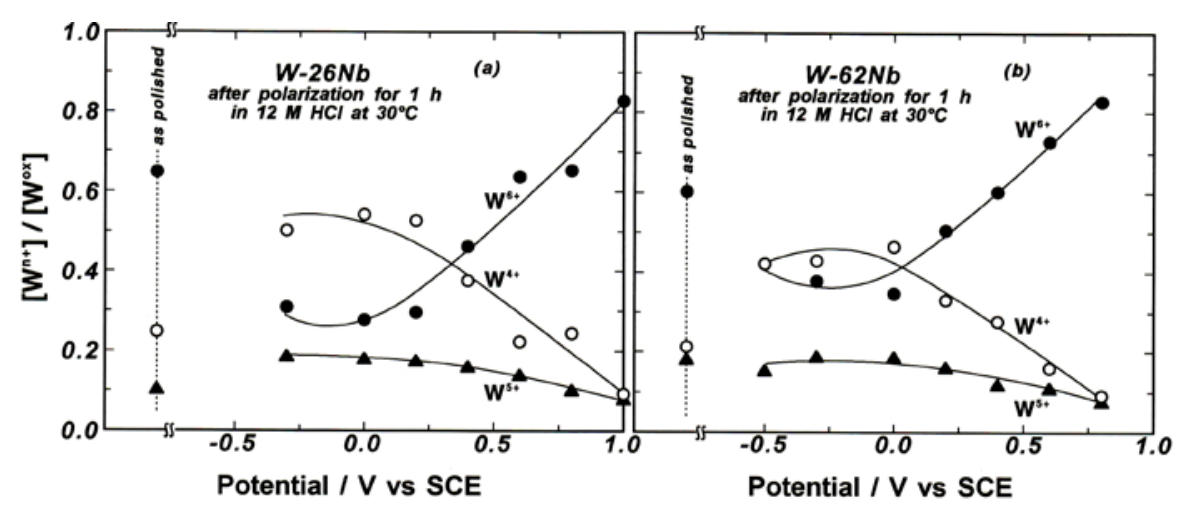

Fig. 7. Changes in the relative ratios of $\mathrm{W}^{4+}, \mathrm{W}^{5+}$ and $\mathrm{W}^{6+}$ ions in the surface films on the (a) $\mathrm{W}$ $26 \mathrm{Nb}$ and (b) W-62Nb alloys after immersion or potentiostatic polarization for $1 \mathrm{~h}$ in $12 \mathrm{M} \mathrm{HCl}$ solution open to air at $30^{\circ} \mathrm{C}$, as a function of polarization potential.

It has been reported that the anodic polarization of W-Ti [22,35], W-Zr [23] and W-Cr $[20,36]$ alloys results in film thickening together with an increase in the ratio of $\mathrm{W}^{6+}$ ions to the total tungsten ions in the passive film. The same trend is observed in this study on $\mathrm{W}$-xNb alloys by anodic polarization in $12 \mathrm{M} \mathrm{HCl}$. With increasing molybdenum content in Cr-Ni-Mo alloys showed high anodic current density similarly to molybdenum metal, which suffers transpassive dissolution by anodic polarization owing to the formation of unstable $\mathrm{Mo}^{6+}$ ions by anodic polarization in $12 \mathrm{M} \mathrm{HCl}$ solution [37]. In contrast to $\mathrm{Mo}^{6+}$ ions, $\mathrm{W}^{6+}$ ions form a relatively stable film in aggressive hydrochloric acid solutions $[20,22,23,28,38]$. As a result, anodic polarization of the $\mathrm{W}$-xNb alloys does not lead to an appreciable increase in the anodic current density corresponding to transpassivation of tungsten, although the film thickness increases.

\subsection{Change in binding energy with composition of anodic film of $\mathrm{W}-\mathrm{xNb}$ alloys}

As shown in Figs 7 (a) and 7(b), the tetravalent tungsten ion is the main oxidation state of tungsten for the $\mathrm{W}-26 \mathrm{Nb}$ and $\mathrm{W}-62 \mathrm{Nb}$ alloys, respectively, at $+0.2 \mathrm{~V}$ (SCE) or lower potentials, while the hexavalent tungsten is the main oxidation state of tungsten at $+0.4 \mathrm{~V}$ (SCE) or higher potentials in $12 \mathrm{M} \mathrm{HCl}$. According to Bhattarai et al. [19], the tetravalent tungsten and pentavalent niobium are located very closely in the spontaneously passivated films formed on the sputter-deposited $\mathrm{W}-\mathrm{Nb}$ alloys so as to show the electronic interaction between $\mathrm{W}^{4+}$ and $\mathrm{Nb}^{5+}$ ions. Now, figures 8 (a) and 8 (b) show the changes in the binding energies of core electrons, that is, $\mathrm{W}^{6+} 4 \mathrm{f}_{7 / 2}$ and $\mathrm{Nb}^{5+} 3 \mathrm{~d}_{5 / 2}$ electrons, respectively, in the anodic passive films on the $\mathrm{W}$-xNb alloys after potentiostatic polarization at $1.0 \mathrm{~V}$ (SCE) for $1 \mathrm{~h}$ in $12 \mathrm{M} \mathrm{HCl}$ solution open to air at $30^{\circ} \mathrm{C}$, as a function of cationic fractions in the anodic passive films. The binding energy of $\mathrm{W}^{6+} 4 \mathrm{f}_{7 / 2}$ electrons decreases with the niobium content of the anodic film, while that of the $\mathrm{Nb}^{5+} 3 \mathrm{~d}_{5 / 2}$ electrons increase with the tungsten content of the film. This implies that charge transfer occurs from $\mathrm{Nb}^{5+}$ to $\mathrm{W}^{6+}$ ion 
and hence tungsten and niobium ions are located very closely in the anodic passive film, so as to show the electronic interaction between $\mathrm{W}^{6+}$ and $\mathrm{Nb}^{5+}$ ions. The same trend of the electronic interaction between $\mathrm{W}^{6+}$ and $\mathrm{Nb}^{5+}$ ions was also observed in the anodic passive films on the $\mathrm{W}$-xNb alloys at $+0.4 \mathrm{~V}$ (SCE) (is not shown here). Accordingly, the anodic passive film on the $\mathrm{W}-\mathrm{xNb}$ alloys is not heterogeneous mixture of tungsten oxyhydroxide consisting of $\mathrm{W}^{6+}$ and $\mathrm{Nb}^{5+}$ ions. Consequently, the passive films of the $\mathrm{W}$-xNb alloys under open circuit condition and at the cathodic potentials consist of double oxyhydroxides of $\mathrm{W}^{4+}$ and $\mathrm{Nb}^{5+}$ ions, and those formed by anodic polarization consist of $\mathrm{W}^{6+}$ and $\mathrm{Nb}^{5+}$ ions.
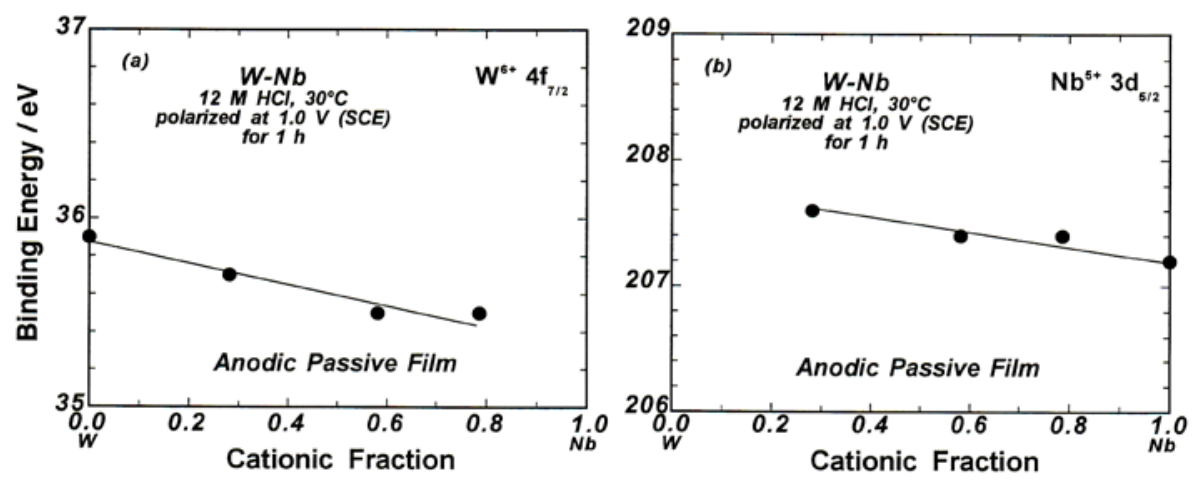

Fig. 8. Changes in the binding energies of (a) $\mathrm{W}^{6+} 4 \mathrm{f}_{7 / 2}$ electrons and $\mathrm{Nb}^{5+} 3 \mathrm{~d}_{5 / 2}$ electrons in the anodic passive films of the sputter-deposited) $\mathrm{W}$-xNb alloys after potentiostatic polarization for $1 \mathrm{~h}$ at $1.0 \mathrm{~V}$ (SCE) in $12 \mathrm{M} \mathrm{HCl}$ solution open to air at $30^{\circ} \mathrm{C}$, as a function of cationic fractions in the anodic passive film.

\section{Conclusions}

A beneficial effect of tungsten and niobium in the anodic passivation of the binary amorphous or nanocrystalline $\mathrm{W}$-xNb alloys was studied using immersion tests, electrochemical measurements and XPS analysis in $12 \mathrm{M} \mathrm{HCl}$ solution open to air at $30^{\circ} \mathrm{C}$. Both alloy-constituting elements (that is, tungsten and niobium) improved the corrosion resistance of the sputter-deposited binary $\mathrm{W}$-xNb alloys synergistically so as they showed lower corrosion rates than those of the alloy-constituting elements in $12 \mathrm{M}$ $\mathrm{HCl}$. The anodic current density of the alloys is decreased with increasing the niobium content in the $\mathrm{W}-\mathrm{xNb}$ alloys, indicating that the protectiveness of the anodic passive films of the $\mathrm{W}-\mathrm{xNb}$ alloys is better than that of tungsten. The XPS analyses clearly revealed that such protectiveness of the anodic films of the alloys is due to the formation of anodic passive double oxyhydroxide films composed mainly of $\mathrm{W}^{6+}$ and $\mathrm{Nb}^{5+}$ ions after potentiostatic polarization for $1 \mathrm{~h}$ in $12 \mathrm{M} \mathrm{HCl}$ solution open to air at $30^{\circ} \mathrm{C}$.

\section{Acknowledgements}


Author would like to express his sincere gratitude to Professor Emeritus; Dr. K. Hashimoto, Dr. K. Asami and Dr. A. Kawashima of IMR of Tohoku University, Sendai and Professor Dr. H. Habazaki of Hokkaido University for their heartful help and discussions on the XPS analyses. Author is thankful to Japan Government and Diaki Ataka Engineering Co. Ltd. for providing an opportunity to visit Tohoku Institute of Technology, Japan as a Visiting Research Fellow.

\section{References}

1. J. Bhattarai, Frontiers of Corrosion Science, $1^{\text {st }}$ edition (Kshitiz Publication, Kathmandu, Nepal, 2010).

2. K. Hashimoto, Rapidly Solidified Alloys; Processes, Structures, Properties, Applications, (ed.) H. H. Liebermann (Marcel Dekker Inc., New York, 1993) p. 591.

3. Di Quarto, S. Piazza and C. Sunseri, In: Passivity of Metals and Semiconductors - Proc. $5^{\text {th }}$ Intl. Symp. Passivity, (ed.) M. Froment (The Societe de Chimie Physique, Bombanners, France, 1983) p. 497.

4. J. W. Johnson and C. L. Wu, J. Electrochem. Soc. 118, 1909 (1971). doi:10.1149/1.2407865

5. M. Naka, K. Hashimoto and T. Masumoto, J. Non-Cryst. Solids 29, 61 (1978). doi:10.1016/0022-3093(78)90140-0

6. N. Bui, A. Irhzo, F. Dabosi and Y. Limouzin-Maire, Corrosion 39, 491 (1983).

7. R. Wang and M. D. Merz, Corros. 40, 272 (1984). doi:10.5006/1.3581953

8. H. Habazaki, A. Kawashima, K. Asami and K. Hashimoto, Proc. Symp. Application Surface Analysis Methods to Environment/Material Interactions, (ed.) D. R. Baer et al. (The Electrochemical Society, Inc., Pennington, USA, 1991) p. 467.

9. H. Habazaki, A. Kawashima, K. Asami and K. Hashimoto, J. Electrochem. Soc. 138, 76 (1991). doi:10.1149/1.2085581

10. R. A. Anderson, E. A. Dobisz, J. H. Perepzko, R. E. Thomas, and J. D. Wiley, Chemistry and Physics of Rapidly Solidified Materials, (ed.) B. J. Berkowizt and R. O. Scattergood (The Metallurgical Soc., AIME, The Fall Meeting'82, St. Louis, Missouri, 1983) p. 111.

11. K. Shimamura, K. Miura, A. Kawashima, K. Asami, and K. Hashimoto, Proc. Symp. Corrosion, Electrochemistry and Catalysis of Metallic Glasses, ed. R. B. and K. Hashimoto (The Electrochemical Society, Pennington, USA, 1988) pp. 232.

12. H. Yoshioka, Q. Yan, H. Habazaki, A. Kawashima, K. Asami, and K. Hashimoto, Corros. Sci. 31, 349 (1990). doi:10.1016/0010-938X(90)90130-W

13. J. H. Kim, E. Akiyama, H. Habazaki, A. Kawashima, K. Asami, and K. Hashimoto, Corros. Sci. 36, 511 (1994). doi:10.1016/0010-938X(94)90040-X

14. P.Y. Park, E. Akiyama, A. Kawashima, K. Asami, and K. Hashimoto, Corros. Sci. 38, 1731 (1996). doi:10.1016/S0010-938X(96)00070-4

15. W. C. Moshier, G. D. Davis, and G. O. Cote, J. Electrochem. Soc. 136, 356 (1998). doi:10.1149/1.2096635

16. K. Hashimoto, H. Habazaki, E. Akiyama, H. Yoshioka, J. H. Kim, P. Y. Park, A. Kawashima, and K. Asami, Sci. Rep. Res. Inst. Tohoku Univ. A42, 99 (1996).

17. M. Mehmood, E. Akiyama, H. Habazaki, A. Kawashima, K. Asami, and K. Hashimoto, Corros. Sci. 42, 361 (2000). doi:10.1016/S0010-938X(99)00077-3

18. J. Bhattarai, Ph.D. Thesis, Tailoring of Corrosion Resistance Tungsten Alloys by Sputtering, Department of Materials Science, Tohoku University, Japan (1998).

19. J. Bhattarai, E. Akiyama, H. Habazaki, A. Kawashima, K. Asami and K. Hashimoto, Corros. Sci. 40, 19 (1998). doi:10.1016/S0010-938X(97)00108-X

20. J. Bhattarai, E. Akiyama, H. Habazaki, A. Kawashima, K. Asami, and K. Hashimoto, Corros. Sci. 40, 1897 (1998). doi:10.1016/S0010-938X(98)00088-2

21. H. Jha and J. Bhattarai, J. Alloys Compds. 456, 474 (2008). doi:10.1016/j.jallcom.2007.02.100 
22. J. Bhattarai, E. Akiyama, A. Kawashima, K. Asami, and K. Hashimoto, Corros. Sci. 37, 2071 (1995). doi:10.1016/0010-938X(95)00120-9

23. J. Bhattarai, E. Akiyama, H. Habazaki, A. Kawashima, K. Asami and K. Hashimoto, Corros. Sci. 39, 353 (1997). doi:10.1016/S0010-938X(97)83351-3

24. J. Bhattarai, E. Akiyama, H. Habazaki, A. Kawashima, K. Asami and K. Hashimoto, Corros. Sci. 40, 155 (1998). doi:10.1016/S0010-938X(97)00106-6

25. J. Bhattarai, E. Akiyama, H. Habazaki, A. Kawashima, K. Asami and K. Hashimoto, Corros. Sci. 40, 757 (1998). doi:10.1016/S0010-938X(97)00177-7

26. J. Bhattarai, Tans. Mater. Res. Soc. Jpn. 35 (1), 1 (2010).

27. J. Bhattarai, Afr. J. Pure Appl. Chem. 5 (8), 212 (2011).

28. H. Habazaki, A. Kawashima, K. Asami and K. Hashimoto, Corros. Sci. 33, 225 (1992). doi:10.1016/0010-938X(92)90147-U

29. K. Hashimoto, Corros. Sci. 49, 42 (2007). doi:10.1016/j.corsci.2006.05.003

30. J. Bhattarai, Research Report, Corrosion Behavior of Sputter-deposited Tungsten-base Alloys, Institute for Materials Research, Tohoku University, Sendai, Japan (1995).

31. K. Asami, J. Electron Spectrosc. Relat. Phenom. 9, 469 (1976). doi:10.1016/0368-2048(76)80065-5

32. K. Asami and K. Hashimoto, Corros. Sci. 17, 559 (1977). doi:10.1016/S0010-938X(77)80002-4

33. A. Kawashima, K. Shimamura, S. Chiba, T. Masunaga, K. Asami, and K. Hashimoto, Proc. $4^{\text {th }}$ Asian-Pacific Corrosion Control Conference, Vol. 2 (Tokyo, Japan, 1985) p. 1042.

34. E. Hirota, H. Yoshioka, H. Habazaki, A. Kawashima, K. Asami, and K. Hashimoto, Corros. Sci. 32, 1213 (1991). doi:10.1016/0010-938X(91)90133-A

35. J. Bhattarai, Nepal J. Sci. Technol. 4, 37 (2002).

36. J. Bhattarai and K. Hashimoto, Tribhuvan Univ. J. 21 (2), 1 (1998).

37. P.Y. Park, E. Akiyama, A. Kawashima, K. Asami, and K. Hashimoto, Corros. Sci. 36, 1395 (1994). doi:10.1016/0010-938X(94)90188-0

38. H. Yoshioka, A. Kawashima, K. Asami, and K. Hashimoto, Corros. Sci. 32, 313 (1991). doi:10.1016/0010-938X(91)90076-2 